\title{
Antioxidant effect of lidocaine and procaine on reactive oxygen species-induced endothelial dysfunction in the rabbit abdominal aorta
}

\author{
Jae Myeong Lee ${ }^{2}$, Jung Kook Suh ${ }^{1}$, Ji Seon Jeong ${ }^{1}$, Sang Yun $\mathrm{Cho}^{1}$, and Dong Won Kim ${ }^{1}$ \\ Department of Anesthesiology and Pain Medicine, College of Medicine, ${ }^{1}$ Hanyang University, ${ }^{2}$ Catholic University of Korea, Seoul, \\ Korea
}

Background: Reactive oxygen species (ROS) induce lipid peroxidation and tissue damage in the endothelium. We tested the antioxidant effect of lidocaine and procaine on ROS-induced endothelial damage in the rabbit aorta.

Methods: Aortic rings isolated from rabbits were suspended in an organ bath filled with Krebs-Henseleit (K$\mathrm{H})$ solution bubbled with $5 \% \mathrm{CO}_{2}$ and $95 \% \mathrm{O}_{2}$ at $37.5^{\circ} \mathrm{C}$. After precontraction with phenylephrine (PE, $\left.10^{-6} \mathrm{M}\right)$, changes in tension were recorded following a cumulative administration of acetylcholine (ACh $3 \times 10^{-8}$ to $\left.10^{-6} \mathrm{M}\right)$. Differences were measured as percentages of ACh-induced relaxation of aortic rings before and after exposure to ROS as generated by electrolysis of the K-H solution. The aortic rings were pretreated with lidocaine or procaine $\left(10^{-5} \mathrm{M}\right.$ to $\left.3 \times 10^{-3} \mathrm{M}\right)$ to compare their effects, as well as ROS scavengers, catalase, mannitol, sodium salicylate, and deferoxamine, and a catalase inhibitor, 3-amino-1,2,4-triazole (3AT).

Results: Lidocaine and procaine dose-dependently maintained endothelium-dependent relaxation induced by ACh despite ROS activity ( $\mathrm{P}<0.05$ vs control value). The 3 AT pretreated procaine $\left(3 \times 10^{-3} \mathrm{M}\right)$ group decreased more significantly than the un-pretreated procaine group $(\mathrm{P}<0.05)$.

Conclusions: These findings suggest that lidocaine and procaine dose-dependently preserve endotheliumdependent vasorelaxation against ROS attack, potentially via hydrogen peroxide scavenging. (Korean J Anesthesiol 2010; 59: 104-110)

Key Words: Catalase, Endothelium, Lidocaine, Procaine, Reactive oxygen species, 3-amino-1,2,4-triazole.

\footnotetext{
Received: April 28, 2010. Revised: 1st, May 3, 2010; 2nd, May 6, 2010. Accepted: May 6, 2010.

Corresponding author: Jung Kook Suh, M.D., Department of Anesthesiology and Pain Medicine, College of Medicine, Hanyang University, 17, Haengdang-dong, Seongdong-gu, Seoul 133-792, Korea. Tel: 82-2-2290-8680, Fax: 82-2-2299-0742, E-mail: jksuh@hanyang.ac.kr The 86th Annual Scientific Meeting of The Korean Society of Anesthesiologists, Poster Session P-138.

This is a theisis for a doctor's degree.

(c) This is an open-access article distributed under the terms of the Creative Commons Attribution Non-Commercial License (http:// creativecommons.org/licenses/by-nc/3.0/), which permits unrestricted non-commercial use, distribution, and reproduction in any medium, provided the original work is properly cited.
} 


\section{Introduction}

Reactive oxygen species (ROS) are normally generated at basal amounts, but ischemia or oxygen re-supply during reperfusion lead to abnormally high ROS levels that cannot be cleared by normal anti-oxidizing systems, causing tissue reperfusion injury [1]. An oxygen $\left(\mathrm{O}_{2}\right)$ molecule generates the intermediate species, superoxide radical $\left(\mathrm{O}_{2}{ }^{\circ}\right)$, hydrogen peroxide $\left(\mathrm{H}_{2} \mathrm{O}_{2}\right)$, and hydroxyl radical $(\mathrm{OH} \cdot)$, during the monovalent reduction reaction, and it is eventually converted to water $\left(\mathrm{H}_{2} \mathrm{O}\right)$ by catalase. In this process, the intermediates $\mathrm{O}_{2} \cdot$ and $\mathrm{OH}^{\cdot}$ are important free radicals that cause peroxidation (LOO') of intracellular lipids and tissue damage [2]. In particular, $\mathrm{OH}$; the most reactive ROS [1], is produced by the Fenton reaction $\left(\mathrm{Fe}^{2+}\right.$ $\left.+\mathrm{HOOH} \rightarrow \mathrm{Fe}^{3+}+\mathrm{OH}^{-}+\mathrm{OH}^{-}\right)$and the Haber-Weiss reaction $\left(\mathrm{O}_{2}{ }^{-}+\mathrm{NO} \rightarrow \mathrm{OONO}^{-}+\mathrm{H}^{+} \rightarrow \mathrm{OONOH} \rightarrow \mathrm{NOO}+\mathrm{OH}^{-}\right)$[3]. ROS generated during reperfusion causes organ damage in the heart $[3,4]$, brain $[5,6]$, and blood vessels $[7,8]$.

In 1980, Furchgott and Zawadzki [9] found an endotheliumderived relaxing factor (EDRF) later shown to be nitric oxide (NO) [10]. Other vasoactive substances, including endotheliumderived hyperpolarizing factor (EDHF) and the endotheliumderived contracting factor (EDCF), are released from the endothelium to regulate vascular tone. However, because the endothelium is composed of a cell monolayer, it is easily damaged by physical and chemical stimuli, including ROS during reperfusion. Inhalation anesthetics $[1,4,11]$ and lidocaine, a local anesthetics, can prevent ischemia-reperfusion injury in the brain [12].

In this study, we tested the effects of lidocaine and procaine, two local anesthetics, on endothelial-dependent relaxation in the rabbit aorta to examine if their anti-oxidizing effects could suppress or reduce the endothelial injury by ROS.

\section{Materials and Methods}

\section{Preparation of ring slices and recording}

All experiments conformed with the regulations of the Laboratory Animal Committee. Under enflurane inhalation anesthesia, ear intravenous injection of heparin $600 \mathrm{IU} / \mathrm{kg}$ was performed on rabbits, with exsanguinations 3 minutes later by cleaving the carotid artery. The abdominal aorta of the rabbits $(2-2.5 \mathrm{~kg}$, Male, $n=27$ ) was extirpated and $3-4 \mathrm{~mm}$ long ring slices were prepared by separating the lipid tissue and connective tissue, not engaging any tension on them, in a petri dish with KrebsHenseleit solution (K-H) solution ( $\mathrm{NaCl}$ 120.0, $\mathrm{NaHCO}_{3} 25.0$, $\mathrm{KCl}$ 5.0, $\mathrm{MgSO}_{4}$ 1.2, $\mathrm{CaCl}_{2} 2.5, \mathrm{NaH}_{2} \mathrm{PO}_{4}$ 1.4, glucose $11.0 \mathrm{mM}$ ) bubbled with $95 \%$ oxygen and $5 \%$ carbon dioxide. Maintaining the temperature at $37 \pm 0.5^{\circ} \mathrm{C}$, one end of the aorta slice was fixed in the tissue bath with $5 \mathrm{ml}$ of $\mathrm{K}-\mathrm{H}$ solution. The opposite end was connected to the force displacement transducer (TSD $125 \mathrm{C}^{\circledR}$, Biopac Inc., USA) and the $\mathrm{K}-\mathrm{H}$ solution was exchanged every 15 minutes during the 90-minute equilibrating period. The final resting tension was fixed at $1.5 \mathrm{~g}$. The vascular smooth muscle tension was recorded through an amplifier (DA100C ${ }^{\circledR}$, Biopac Inc.) with a data acquisition system (MP100 ${ }^{\circledR}$, Biopac Inc.) and a personal computer.

Following the precontraction with phenylephrine (PE) $10^{-6}$ $\mathrm{M}$, acetylcholine (ACh) $3 \times 10^{-8}, 10^{-7}, 3 \times 10^{-7}$, and $10^{-6} \mathrm{M}$ were consecutively administered to observe the percent change (\%) of the aortic tone. Changes of the aortic tone by ACh administration before ROS exposure (control) and after ROS exposure (experimental) were compared.

\section{Method of ROS exposure}

ACh-induced contractions were measured before and after electrolysis (EL) with an electric current (constant current, 15 $\mathrm{mA}$ ) to the positive and negative electrodes in the K-H solution for 35 seconds to generate ROS and induce endothelial injury. More than $1 \mathrm{~cm}$ was maintained between the abdominal aorta ring slices and the positive and negative electrodes to avoid a direct stimulus of the electric field to the tissue. The K-H solution was then exchanged, followed by precontraction with $\mathrm{PE}$ and the second ACh treatment.

\section{Vascular relaxation in the ROS scavenger pretreatment}

To examine the action of the scavenger on ROS, 1,000 U/ $\mathrm{ml}$ of catalase $(\mathrm{n}=8)$, the hydrogen peroxide scavenger, was pretreated for 15 minutes. The hydroxyl radical scavengers, deferoxamine $(\mathrm{n}=9) 0.1 \mathrm{mM}$, sodium salicylate $1 \mathrm{mM}(\mathrm{n}=8)$, and mannitol $5 \times 10^{-3} \mathrm{M}(\mathrm{n}=12)$ were also pretreated, each for 30 minutes. Then, ROS was generated by EL to induce endothelial injury.

\section{The lidocaine and procaine pretreatment groups}

Experimental group values were obtained by 15 minutes of reagent pretreatment followed by ROS exposure. The experimental groups included pretreatment with lidocaine (L : $\mathrm{n}=13,13,12,10,13,11)$ or procaine $(\mathrm{P}: \mathrm{n}=6,15,12,8,10,12)$ at concentrations of $10^{-5}, 3 \times 10^{-5}, 10^{-4}, 3 \times 10^{-4}, 10^{-3}$, and $3 \times 10^{-3} \mathrm{M}$.

\section{Effect of 3-amino-1,2,4-triazole (3AT) on endothelial injury by ROS}

The samples were pretreated with 3AT, a catalase inhibitor, for 30 minutes. After a 15-minute waiting period, $3 \times 10^{-4} \mathrm{M}$ of lidocaine 
$(n=6)$ and procaine $(n=8)$ were pretreated for 15 minutes. Following 35 seconds of EL to generate ROS, ACh was added.

\section{Reagents}

All reagents, PE, ACh, lidocaine, procaine, catalase, defeoxamine, sodium salicylate, mannitol, and 3AT, were purchased from Sigma Co. (USA).

\section{Statistical procedure}

The degree of aortic tone relaxation by ACh was calculated as a percentage for control group values. Data are presented as mean \pm SE. Prism 2.0 ${ }^{\circledR}$ (GraphPad Software, San Diego, CA, USA) was used to obtain the dose-response curve by non-linear regression analysis. A paired t-test was used for the comparison of changes in each ring slice before and after ROS exposure, while an unpaired t-test was used for the comparison of the aortic tone after ROS exposure between the 3AT pretreated group and the non-pretreated group. For analysis of pretreated local anesthetic concentrations, a one-way ANOVA was used. All the post-hoc tests used the Dunnett test, with statistical significance as $\mathrm{P}<0.05$.

\section{Results}

\section{Vascular relaxation after ROS scavenger pretreatment}

At ACh $10^{-6}$, the tension before ROS scavenger pretreatment was $-87.6 \pm 3.9 \%$, and the endothelial-dependent relaxation was

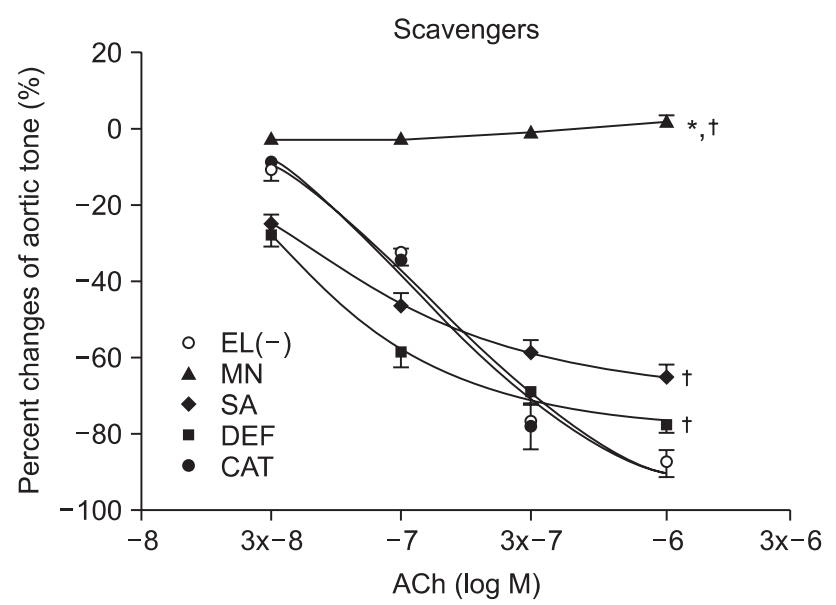

Fig. 1. Scavengers efficiency against ROS attacks are shown in order of catalase (CAT, $n=8$ ), deferoxamine (DEF, $n=9$ ), and sodium salicylate $(\mathrm{SA}, \mathrm{n}=8)$. Mannitol ( $\mathrm{MN}, \mathrm{n}=12$ ) has no scavenging effect. Data are expressed as mean \pm SE. n: number, ACh: acetylcholine, $\operatorname{EL}(-)$ : before electrolysis. ${ }^{*} \mathrm{P}<0.05$, compared with $\mathrm{ACh} 10^{-7}$ to $10^{-6} \mathrm{M}$ of $\mathrm{EL}(-)$, ${ }^{\dagger} \mathrm{P}<0.05$, compared with ACh $10^{-7}$ to $10^{-6} \mathrm{M}$ of the CAT group.
$-87.6 \pm 3.3,-77.6 \pm 2.3,-65.6 \pm 3.3$, and $2.0 \pm 1.8 \%$ with catalase, deferoxamine, sodium salicylate, and mannitol, respectively. The catalsase group was not affected by ROS, but the relaxation was significantly reduced in the other groups $(\mathrm{P}<0.05$, Fig. 1$)$. The mannitol group did not show endothelial-dependent relaxation.

\section{Vascular relaxation after endothelial injury with ROS}

Lidocaine dose-dependently reduced the relaxation by ACh $10^{-7}$, $3 \times 10^{-7}$, and $10^{-6} \mathrm{M}$ after ROS exposure (P $<0.05$, Fig. 2 and 3 ).

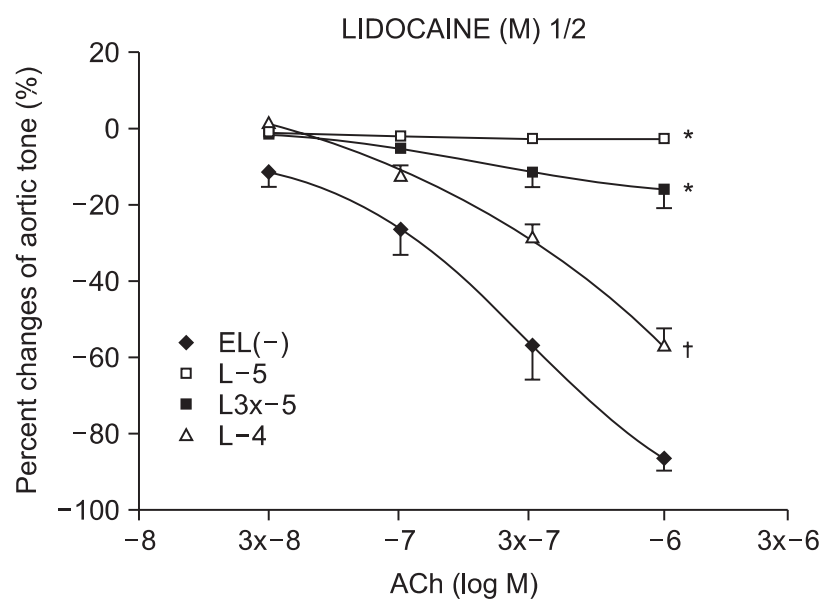

Fig. 2. Effect of low doses of lidocaine pretreatment (L-5: $10^{-5}$ L3x-5: $3 \times 10^{-5}, \mathrm{~L}-4: 10^{-4} \mathrm{M}$ ) on the reactive oxygen species (ROS) attack. Data are presented as mean \pm SE. ACh: acetylcholine, $\operatorname{EL}(-)$ : before electrolysis. ${ }^{*} \mathrm{P}<0.05$, compared with ACh $10^{-7}$ to $10^{-6} \mathrm{M}$ of $\mathrm{EL}(-),{ }^{\dagger} \mathrm{P}<0.05$, compared with ACh $10^{-7}$ to $10^{-6} \mathrm{M}$ of the lidocaine $10^{-5} \mathrm{M}(\mathrm{L}-5)$ group.

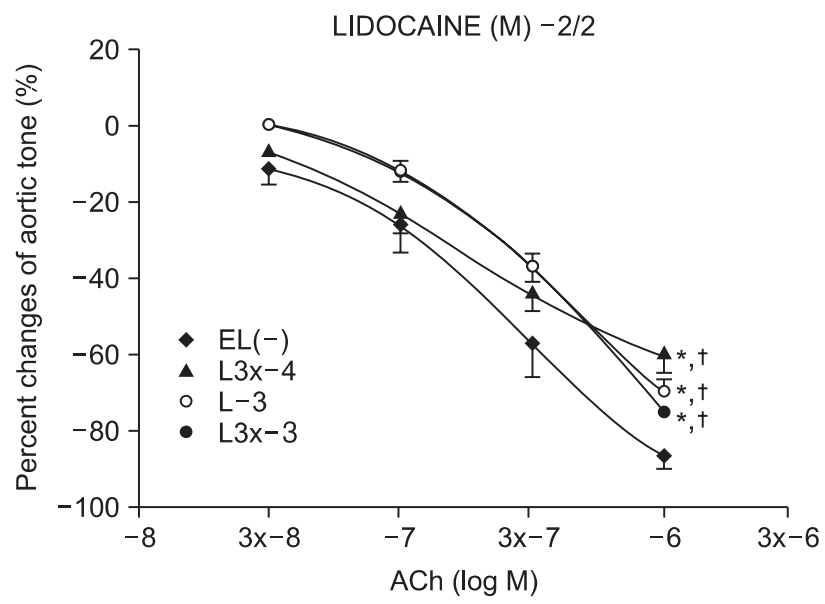

Fig. 3. Effect of high doses of lidocaine (L3x-4: $3 \times 10^{-4}$, L-3: $10^{-3}$, L3x-3: $3 \times 10^{-3} \mathrm{M}$ ) on the reactive oxygen species (ROS) attack. Data are presented as mean \pm SE. ACh: acetylcholine, $\operatorname{EL}(-)$ : before electrolysis. ${ }^{*} \mathrm{P}<0.05$, compared with ACh $10^{-7}$ to $10^{-6} \mathrm{M}$ of $\mathrm{EL}(-)$, ${ }^{\dagger} \mathrm{P}<0.05$, compared with ACh $10^{-7}$ to $10^{-6} \mathrm{M}$ of the lidocaine $10^{-5} \mathrm{M}$ (L-5) group. 


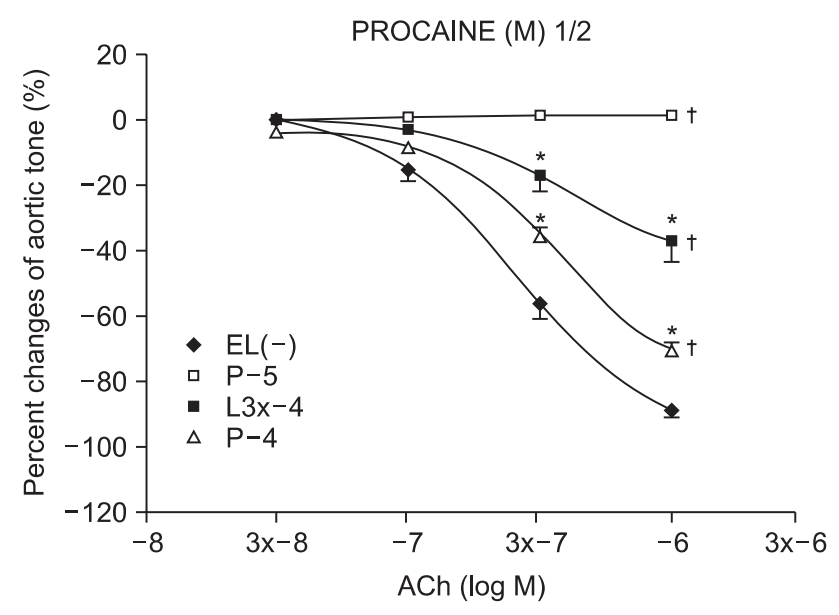

Fig. 4. Effect of low doses of procaine (P-5: $10^{-5}, \mathrm{P} 3 \mathrm{x}-5: 3 \times 10^{-5}$, P-4: $10^{-4} \mathrm{M}$ ) on the reactive oxygen species (ROS) attack. Data are presented as mean \pm SE. ACh: acetylcholine, $\operatorname{EL}(-)$ : before electrolysis. ${ }^{*} \mathrm{P}<0.05$, compared with ACh $10^{-7}$ to $10^{-6} \mathrm{M}$ of $\operatorname{EL}(-)$, ${ }^{\dagger} \mathrm{P}<0.05$, compared with the procaine $10^{-5} \mathrm{M}(\mathrm{P}-5)$ group.

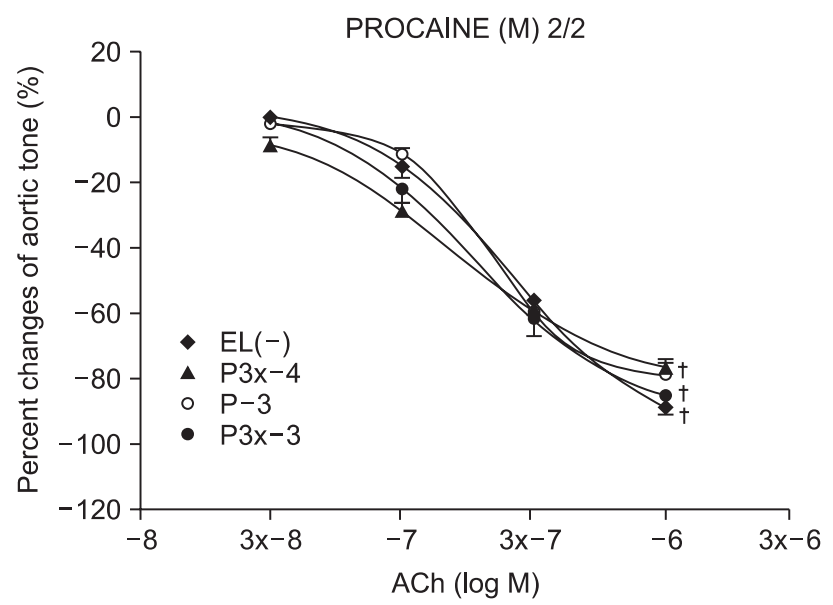

Fig. 5. Effect of high doses of procaine (P3x-4: $3 \times 10^{-4}, \mathrm{P}^{-3}: 10^{-3}$, P3X-3: $3 \times 10^{-3} \mathrm{M}$ ) on the reactive oxygen species (ROS) attack. Data are presented as mean \pm SE. ACh: acetylcholine, $\operatorname{EL}(-)$ : before electrolysis. ${ }^{\dagger} \mathrm{P}<0.05$, compared with ACh $10^{-7}$ to $10^{-6} \mathrm{M}$ of the procaine $10^{-5} \mathrm{M}(\mathrm{P}-5)$ group.

Similarly, procaine dose-dependently reduced the relaxation induced by ACh when compared with that before the ROS exposure $(\mathrm{P}<0.05$, Fig. 4 and 5$)$.

\section{Effect of 3AT on the endothelial injury by ROS}

3AT with lidocaine did not affect lidocaine activity (Fig. 6), but did reduce the relaxation induced by $10^{-6} \mathrm{M}$ ACh after procaine pretreatment $(\mathrm{P}<0.0141$, Fig. 7$)$.

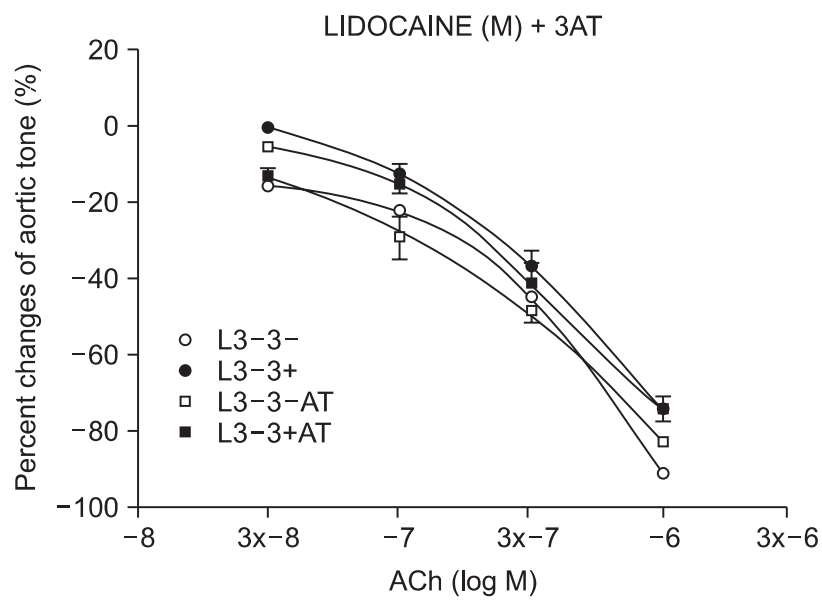

Fig. 6. The antioxidant effect of the lidocaine $3 \times 10^{-3} \mathrm{M}(\mathrm{L} 3 \mathrm{x}-3+)$ group is not attenuated by the pretreatment of 3AT (L3x-3+AT). Data are presented as mean \pm SE. Before electrolysis: L3X-3-, L3X-3-AT. ACh: acetylcholine. 3AT: 3-Amino-1,2,3-Triazole.

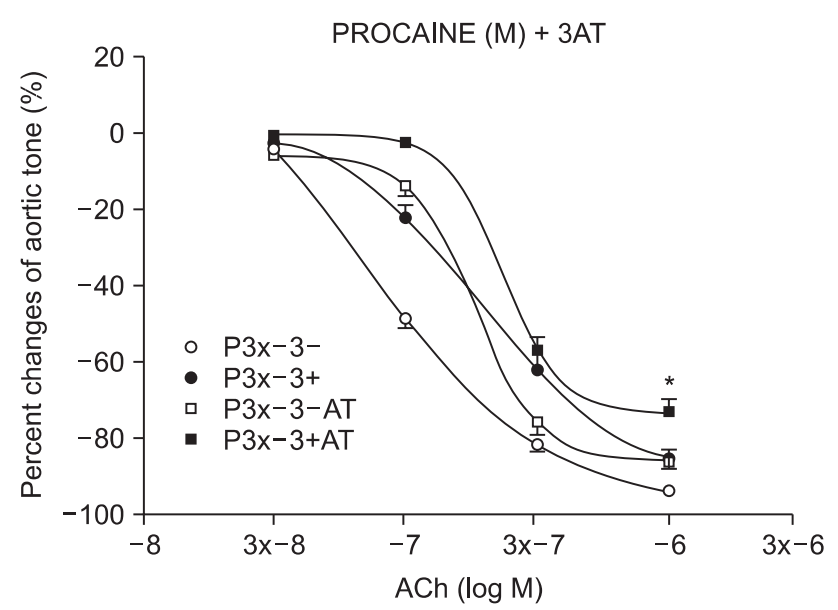

Fig. 7. The antioxidant effect of the procaine $3 \times 10^{-3} \mathrm{M}(\mathrm{P} 3 \mathrm{x}-3+)$ group is significantly attenuated by the pretreatment with $3 \mathrm{AT}$ (P3X$3+\mathrm{AT}$ ). Data are presented as mean \pm SE. Before electrolysis: P3x-3-, P3X-3-AT. ACh: acetylcholine. 3AT: 3-Amino-1,2,3-Triazole. ${ }^{*} \mathrm{P}<0.05$, compared with the procaine $3 \times 10^{-3} \mathrm{M}$ (P3x-3+) group.

\section{Discussion}

We generated ROS by direct EL of a physiologic salt solution (PSS), such as the K-H solution [8], and the other researchers are directly injecting $\mathrm{H}_{2} \mathrm{O}_{2}$ to PSS [13]. ROS such as $\mathrm{O}_{2}, \mathrm{H}_{2} \mathrm{O}_{2}$, and $\mathrm{OH}^{\cdot}$ are generated during PSS EL [14-17]. We did not add normal levels of ascorbic acid $\left(1.1 \times 10^{-4} \mathrm{M}\right)$ to exclude its antioxidizing effect. A number of tiny air bubbles were generated at the positive and negative electrodes when the electric current was applied. In mouse thoracic aorta, 5 minutes of EL 
is sufficient to induce ROS injury [8]. However, 5 minutes of EL with $15 \mathrm{~mA}$ constant current caused too much injury in our model, so we used a 35-second treatment, indicating that there are species differences in the degree of injury by ROS.

Lecour et al. [18] verified that the function of the left ventricle declined when ROS was generated by 1 minute of EL in the K-H solution with a constant current of $1,1.5,3,5,7.5$, and $10 \mathrm{~mA}$, as measured by the Langendorff perfusion method. Superoxide radicals and hydroxyl radicals were also generated by the reaction of the 5, 5-dimethyl-1-pyrroline-N-oxide (DMPO)$\mathrm{OH}$ signal, the adduct of DMPO EL, with superoxide dismutase (SOD : $100 \mathrm{IU} / \mathrm{ml}$ ) and mannitol $(50 \mathrm{mM}$ ), followed by a quantitative analysis with electron spin resonance. The DMPO$\mathrm{OH}$ signal occurred as early as 10 seconds after starting EL and was maintained for 60 seconds, with diminishing levels after EL stopped. SOD pretreatement reduced the DMPO-OH signal by $60 \%$, which showed that the hydroxyl radical generation process was partially by the Fenton reaction of a superoxide radical. Mannitol (50 mM) blocked the DMPO-OH signal but did not change cardiac parameters after EL [18]. Similarly, pretreatment of mannitol a scavenger of hydroxyl radicals, did not prevent endothelial dysfunction in our model.

ROS is also generated via cyclooxygenase during an inflammatory response [19]. Endotheliocytes, Kuffer cells, neutrophils, and macrophages also produce ROS and reactive nitrogen species (RNS) during an inflammatory response via antagonizing pathogenic bacteria in those cells. Antioxidant defenses are depleted by chronic exposure to ROS or RNS, leading to cancers, rheumatoid arthritis, or organ transplantation rejection. Large inflammatory responses also produce ROS, including peroxyl radical (ROO), hydroxyl radical, superoxide radical, and hydrogen peroxide, and RNS, including $\cdot \mathrm{NO}$ and peroxynitrite anion $\left(\mathrm{ONOO}^{-}\right)$.

Vascular relaxation induced by ACh is caused by inducing NO release in endotheliocytes, and ROS inactivates NO [20,21]. In addition, ROS generated by ischemia or reperfusion causes endothelial damage $[15,22]$. We generated ROS with 35 seconds of EL and then replaced the K-H solution for measurements after 15 minutes of equilibrium. Thus, ACh should induce vascular relaxation via changes in endothelial injury and not from inactivation of NO [20]. The endothelial monolayer is easily damaged and dysfunctional during chronic hypertension, even to the point of detachment [23]. Smooth muscle may also be directly injured by ROS.

During oxygen depletion, such as ischemia, ATP in the endothelium is rapidly consumed, causing failure of the $\mathrm{Na}^{+}-\mathrm{K}^{+}$ATPase pump and an increase of intracellular $\left[\mathrm{Na}^{+}\right]$ $\mathrm{i}$ and $\left[\mathrm{H}^{+}\right] \mathrm{i}$ by inhibiting the removal of the metabolites and mitochondrial NADH oxidation. Increased intracellular $\left[\mathrm{H}^{+}\right]$ i leads to an increase in $\left[\mathrm{Na}^{+}\right] \mathrm{i}$ by facilitating $\mathrm{Na}^{+}-\mathrm{H}^{+}$exchange to maintain constant $[\mathrm{pH}] \mathrm{i}$ and thus triggers the $\mathrm{Na}^{+}-\mathrm{Ca}^{2+}$ exchange, increasing $\left[\mathrm{Ca}^{2+}\right] \mathrm{i}$ as well $[24]$. Increased $\left[\mathrm{Ca}^{2+}\right]$ i deforms proteins and phospholipids [25] via activation of phospholipase $\mathrm{A}_{2}$ to generate arachidonic acid (AA), a free fatty acids. AA is then converted to prostanoids such as prostacyclin $\left(\mathrm{PGI}_{2}\right)$, a strong smooth muscle relaxant, and prostaglandin $\mathrm{G}$, a constrictor, to thromboxane $\mathrm{A}_{2}\left(\mathrm{TXA}_{2}\right)$ or to leukotrienes (LT), which cause the synechia of leukocytes to endotheliocytes. In addition, it facilitates the conversion of xanthine dehydrogenase to xanthine oxygenase (XO) and increases the intracellular superoxide radical $\left(\mathrm{O}_{2}{ }^{\cdot}\right)$ [23]. Oxygen re-supply after ischemia increases ROS: $\mathrm{O}_{2} \cdot \mathrm{OH}^{\circ}$, and LOO [26]. These ROS that are generated mainly in mitochondria of neutrophil [25] denature lipids and proteins and damage the cell membrane and mitochondria (mitochondrial permeability transition pore, MPTP) [27], and denature enzymes [25]. $\mathrm{O}_{2} \cdot$ is the first ROS is generated by oxygen re-supply; it is produced by XO or by LT from neutrophils and nerve cells in the microvascular structure. Superoxide radical is converted by SOD to hydrogen peroxide, which eventually becomes water $\left(\mathrm{H}_{2} \mathrm{O}\right)$ by catalase. Here, catalase $(1,000 \mathrm{U} / \mathrm{ml})$ pretreatment prevented endothelial injury by ROS and maintained endothelial-dependent aorta relaxation. However, excess $\mathrm{O}_{2} \cdot$ is converted by the Fenton reaction and Haber-Weiss reaction to a hydroxyl radical, which causes the severe injury and eventually causes lipids peroxidation and cell and tissue injury by LOO generation [26]. Pretreatment with mannitol $(5 \mathrm{mM})$ as the $\mathrm{OH} \cdot$ scavenger did not prevent endothelial injury, potentially because ROS sensitivity may shows species variation and higher doses may be needed.

Lidocaine protects against brain ischemia by reducing energy demand [28]. Anoxia-induced depolarization in the mouse hippocampus pretreated with lidocaine $1 \mu \mathrm{M}$ and $0.25 \mu \mathrm{M} 15$ minutes before the ischemia-induction started after 49 seconds and 44 seconds, respectively, indicating a depolarization delay compared to the 27-second interval in the control group. The amount of ATP in the lidocaine pretreated group increased to $165 \%$ and $212 \%$ of controls at 1 minute and 2 minutes after ischemia, respectively. The activity of $\mathrm{Na}^{+}-\mathrm{K}^{+}$ATPase and the activity of $\mathrm{Ca}^{2+}$ ATPase were not changed, and $\left[\mathrm{Ca}^{2+}\right]$ i did not increase [28]. These findings imply that lidocaine maintains energy by delaying neuronal depolarization. In addition, $\left[\mathrm{Ca}^{2+}\right]$ $i$ increased in the left ventricle of the excised mouse heart where dysfunction was induced by hydrogen peroxide, but pretreatment with lidocaine $10 \mu \mathrm{M}$ blocked this increase [29].

In human microvascular endothelial cells (HMVEC), lipopolysacharide in the culture solution caused necrosis of the endotheliocytes; amide local anesthetic pretreatment prevented this necrosis, but tetracaine and procaine, the esters, could not [30]. The protection by amide local anesthetics, 
including lidocaine, was blocked by 5 -hydroxydecanoate (5HD), indicating that the mitochondrial ATP-sensitive $\mathrm{K}^{+}$ channel (mito $\left[\mathrm{K}^{+}{ }_{\text {ATP }}\right]$ ) is involved in the effect, consistent with the mechanism of ischemia-reperfusion injury. Because EL-induced injury from ROS involves direct injury by ROS that have not undergone the cascade reactions caused in the preconditioned cells, 5-HD pretreatment did not block the endothelial-protecting effect of lidocaine and procaine, indicating that mito $\left[\mathrm{K}^{+}{ }_{\text {ATP }}\right]$ was not involved (data not shown).

We have tested whether ROS causes dysfunction in the rabbit aorta endothelium after lidocaine and procaine pretreatment. Lidocaine and procaine both dose-dependently protected endothelial-dependent relaxation by removing or anti-oxidizing ROS. Although lidocaine was less potent, both showed similar efficacy. In conclusion, pretreatment with lidocaine and procaine dose-dependently showed anti-oxidizing or ROSremoving effects to protect endothelial-dependent relaxation in the abdominal aorta after ROS exposure. Procaine could remove hydrogen peroxide as part of its protection mechanism.

\section{References}

1. Wilson JX, Gelb AW. Free radicals, antioxidants, and neurologic injury: possible relationship to cerebral protection by anesthetics. J Neurosurg Anesthesiol 2002; 14: 66-79.

2. Hess ML, Manson NH. Molecular oxygen: friend and foe. The role of the oxygen free radical system in the calcium paradox, the oxygen paradox and ischemia/reperfusion injury. J Mol Cell Cardiol 1984; 16: 969-85.

3. Lalu MM, Wang W, Schulz R. Peroxynitrite in myocardial ischemiareperfusion injury. Heart Fail Rev 2002; 7: 359-69.

4. Kato R, Foëx P. Myocardial protection by anesthetic agents against ischemia-reperfusion injury: an update for anesthesiologists. Can J Anaesth 2002; 49: 777-91.

5. Hwang YS, Shin CY, Huh Y, Ryu JH. Hwangryun-Hae-Dok-Tang (Huanglian-Jie-Du-Tang) extract and its constituents reduce ischemia-reperfusion brain injury and neutrophil infiltration in rats. Life Sci 2002; 71: 2105-17.

6. Kapinya KJ, Prass K, Dirnagl U. Isoflurane induced prolonged protection against cerebral ischemia in mice: a redox sensitive mechanism? Neuroreport 2002; 13: 1431-5.

7. Brodsky SV, Yamamoto T, Tada T, Kim B, Chen J, Kajiya F, et al. Endothelial dysfunction in ischemic acute renal failure: rescue by transplanted endothelial cells. Am J Physiol Renal Physiol 2002; 282: F1140-9.

8. Gumusel B, Tel BC, Demirdamar R, Sahin-Erdemli I. Reactive oxygen species-induced impairment of endothelium-dependent relaxation in rat aortic rings: protection by L-arginine. Eur J Pharmacol 1996; 306: 107-12.

9. Furchgott RF, Zawadzki JV. The obligatory role of endothelial cells in the relaxation of arterial smooth muscle by acetylcholine. Nature 1980; 288: 373-6.

10. Palmer RM, Ferrige AG, Moncada S. Nitric oxide release accounts for the biological activity of endothelium-derived relaxing factor. Nature 1987; 327: 524-6.

11. Ebel D, Preckel B, You A, Mullenheim J, Schlack W, Thamer V. Cardioprotection by sevoflurane against reperfusion injury after cardioplegic arrest in the rat is independent of three types of cardioplegia. Br J Anaesth 2002; 88: 828-35.

12. Shokunbi MT, Gelb AW, Wu XM, Miller DJ. Continuous lidocaine infusion and focal feline cerebral ischemia. Stroke 1990; 21: 107-11.

13. Kil HK, Kim WO, Kim SH, Nam YT. Effects of isoflurane and propofol on hydrogen peroxide-induced injury of trachea in guinea-pig. Korean J Anesthesiol 1999; 37: 303-10.

14. Lamb FS, King CM, Harrell K, Burkel W, Webb RC. Free radicalmediated endothelial damage in blood vessels after electrical stimulation. Am J Physiol 1987; 252: H1041-6.

15. Lamb FS, Webb RC. Vascular effects of free radicals generated by electrical stimulation. Am J Physiol 1984; 247: H709-14.

16. Jackson CV, Mickelson JK, Stringer K, Rao PS, Lucchesi BR. Electrolysis-induced myocardial dysfunction. A novel method for the study of free radical mediated tissue injury. J Pharmacol Methods 1986; 15: 305-20.

17. Jackson CV, Mickelson JK, Pope TK, Rao PS, Lucchesi BR. $\mathrm{O}_{2}$ free radical-mediated myocardial and vascular dysfunction. Am J Physiol 1986; 251: H1225-31.

18. Lecour S, Baouali AB, Maupoil V, Chahine R, Abadie C, JavouheyDonzel A, et al. Demonstration of the production of oxygencentered free radicals during electrolysis using E.S.R. spin-trapping techniques: effects on cardiac function in the isolated rat heart. Free Radic Biol Med 1998; 24: 573-9.

19. Fernandes E, Costa D, Toste SA, Lima JL, Reis S. In vitro scavenging activity for reactive oxygen and nitrogen species by nonsteroidal anti-inflammatory indole, pyrrole, and oxazole derivative drugs. Free Radic Biol Med 2004; 37: 1895-905.

20. Gryglewski RJ, Palmer RM, Moncada S. Superoxide anion is involved in the breakdown of endothelium-derived vascular relaxing factor. Nature 1986; 320: 454-6.

21. Rubanyi GM, Vanhoutte PM. Superoxide anions and hyperoxia inactivate endothelium-derived relaxing factor. Am J Physiol 1986; 250: H822-7.

22. Chen X, Gillis CN. Effect of free radicals on pulmonary vascular response to acetylcholine. J Appl Physiol 1991; 71: 821-5.

23. Lockette W, Otsuka Y, Carretero O. The loss of endotheliumdependent vascular relaxation in hypertension. Hypertension 1986; 8: II61-6.

24. Opie LH. Oxygen lack: ischemia and angina. In: The Heart. Physiology, from Cell to Circulation. 3rd ed. Edited by Opie LH: Philadelphia, Lippincott-Ravens Publishers. 1998, pp 513-41.

25. Opie LH. Myocardial reperfusion: new ischemic syndrome. In: The Heart. Physiology, from Cell to Circulation. 3rd ed. Edited by Opie LH: Philadelphia, Lippincott-Ravens Publishers. 1998, pp 563-88.

26. Safar P, Birtcher NG. Prolonged life support: post-reperfusion syndrome. In: Cardiopulmonary Cerebral Resuscitation. 3rd ed. Edited by Safar P, Birtcher NG: Philadelphia, WB Saunders Co. 1988, p 237.

27. Aronis A, Komarnitsky R, Shilo S, Tirosh O. Membrane depolarization of isolated rat liver mitochondria attenuates permeability transition pore opening and oxidant production. Antioxid Redox 
Signal 2002; 4: 647-54.

28. Seyfried FJ, Adachi N, Arai T. Suppression of energy requirement by lidocaine in the ischemic mouse brain. J Neurosurg Anesthesiol 2005; 17: 75-81

29. Wang L, Lopaschuk GD, Clanachan AS. H(2)O(2)-induced left ventricular dysfunction in isolated working rat hearts is indepen- dent of calcium accumulation. J Mol Cell Cardiol 2008; 45: 787-95. 30. de Klaver MJ, Weingart GS, Obrig TG, Rich GF. Local anestheticinduced protection against lipopolysaccharide-induced injury in endothelial cells: the role of mitochondrial adenosine triphosphatesensitive potassium channels. Anesth Analg 2006; 102: 1108-13. 